\title{
Drilling of Titanium/CFRP/Aluminium Stacks
}

\author{
Islam Shyha ${ }^{1, a}$, Sein Leung Soo ${ }^{1, b}$, David K. Aspinwall ${ }^{1, c}$, Sam Bradley,e, \\ Stuart Dawson ${ }^{3, e}$, Cornelius J. Pretorius ${ }^{4, f}$ \\ ${ }^{1}$ School of Mechanical Engineering, University of Birmingham, Birmingham, UK \\ ${ }^{2}$ Composite Research Centre, GKN Aerospace, Isle of Wight, UK \\ ${ }^{3}$ Aerospace Development, Unimerco Ltd, Staffordshire, UK \\ ${ }^{4}$ Element Six Advanced Materials, Element Six Ltd, Shannon, Ireland \\ aies628@bham.ac.uk, bsoosl@bham.ac.uk, cd.k.aspinwall@bham.ac.uk, \\ 'sam.bradley@ukes.aerospace.gknplc.com, ${ }^{\mathrm{e}}$ swd@unimerco.com, ${ }^{\mathrm{f}}$ neels.pretorius@e6.com
}

Keywords: Drilling, titanium/CFRP/aluminium stack, cutting forces

\begin{abstract}
Following a review on the machinability of CFRP composites and multilayer stacks typically comprising metallic and composite material elements, the paper details experimental results when drilling $30 \mathrm{~mm}$ thick titanium/CFRP/aluminium workpiece stacks. Testing utilised a modified fractional factorial design based on an L18 Taguchi orthogonal array. This comprised four factors, three of which were at three levels and one at two levels and involved tool coating, cutting speed, feed rate and machining environment. Tools evaluated involved hardmetal and diamond coated carbide in addition to uncoated tungsten carbide drills. Response variables were principally tool wear and cutting force/torque with an end of test criteria of $300 \mu \mathrm{m}$ flank wear. Peeling of the CVD diamond coating occurred within the first several holes drilled however this was not a limiting factor in terms of tool life. Principal damage occurred when drilling through the titanium (Ti-6Al$4 \mathrm{~V}$ ) rather than the aluminium (Al 7050) or CFRP (unidirectional "UD" laminates) sections. Best tool life/performance ( 310 drilled holes) was obtained with the more conventional uncoated carbide drills at lower cutting speed and feed rate. Typically thrust forces increased from $300 \mathrm{~N}$ for the first hole to $\sim 2200 \mathrm{~N}$ for last hole drilled while torque values were generally below $600 \mathrm{~N}$.cm for worn tools.
\end{abstract}

\section{Introduction}

Substantial benefits in terms of high specific strength (up to $1200 \mathrm{kN} \cdot \mathrm{m} / \mathrm{kg}$ ), material stiffness (up to $520 \mathrm{GPa}$ modulus of elasticity), low density and excellent damping properties have seen carbon fibre reinforced plastic (CFRP) composites increasingly replace traditional metallic alloys such as aluminium and titanium within the aircraft fuselage, for wing spars and aeroengine fan blades. Consequently, research into the machinability of CFRP and the drilling process in particular has accelerated over the past $10-12$ years, both in industry and academia. Aspects investigated have encompassed the effects of operating parameters [1], drill type [2, 3], tool coatings [4] and material/fibre orientation $[5,6]$ on various output measures including tool life, thrust forces, surface roughness, hole accuracy etc. A key challenge however is the elimination/reduction of hole entry/exit delamination as such flaws are known to adversely affect joint integrity and operating lifespan [7].

The combination of CFRP with titanium and aluminium to form multi-layered material stacks has also gained prominence in recent years especially for applications involving aerospace structures subject to extreme mechanical loads in service. The joining of these materials typically requires the production of fastener holes. At present, such holes for wing and tail plane components are manufactured via a multi-shot routine which necessitates pre-drilling of each individual layer followed by a deburring cycle. The stack is then assembled and temporarily held together (mechanically) prior to hole reaming, although even here the disparity in workpiece mechanical 
properties (e.g. different elastic modulus, thermal expansion coefficient etc.), often presents an obstacle towards achieving the required tolerance level. Relatively low cutting speeds involving manual drilling together with low feed rates are usually employed resulting in extensive fabrication times (typically of the order of several minutes per hole). In addition, the high tool wear rates encountered when drilling CFRP and titanium further impacts on process productivity.

Contrary to the machining of CFRP's, published information on the drilling of 3 layer metal/composite materials is extremely limited. However, a key paper on the topic by Brinksmeier and Janssen [8], describes some of the difficulties associated with through drilling of $\mathrm{Al} / \mathrm{CFRP} / \mathrm{Ti}$ stacks using uncoated and coated tungsten carbide tools. These include low tool life $(\sim 30$ holes $)$, clogging of drill flutes due to poor evacuation of continuous titanium chips from the bottom layer and severe damage/erosion of the CFRP hole surface caused by sharp Ti swarf, see Fig. 1(a). Support offered to the CFRP laminate by the Al and Ti plates is anticipated to inhibit delamination of the composite surfaces during drilling in accordance with data reported by Tsao and Hocheng [9], where use of a backup layer ( $2 \mathrm{~mm}$ thick $\mathrm{Al}$ plate) was seen to impede the progress of laminate failure, see Fig. 1(b). Additionally, reduced burr formation by the titanium and aluminium material at the interface with the CFRP layer can also be expected [10]. The current paper details results from experimental research on the performance of various coated/uncoated WC tools and the effect of operating parameters when drilling composite/metallic stacks of Ti/CFRP/Al in a single shot operation.

(a)

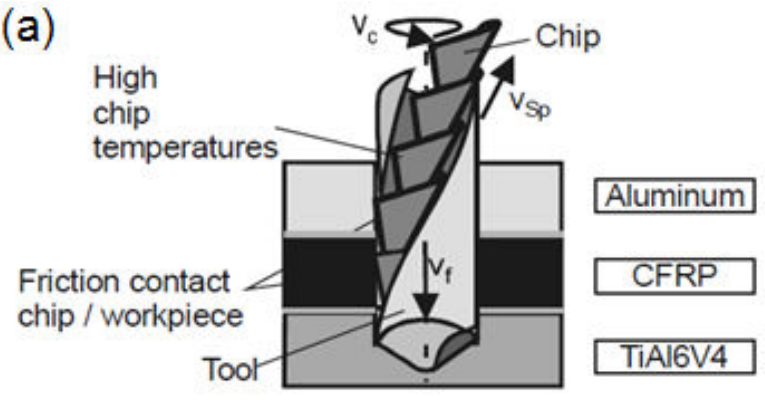

(b)

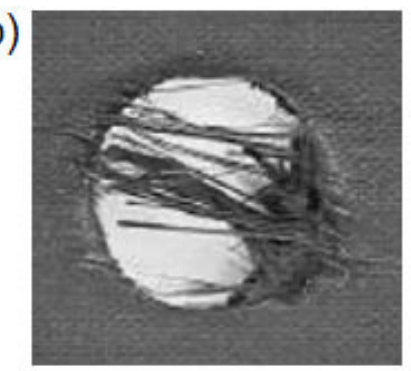

Hole drilled without backup Hole drilled with backup

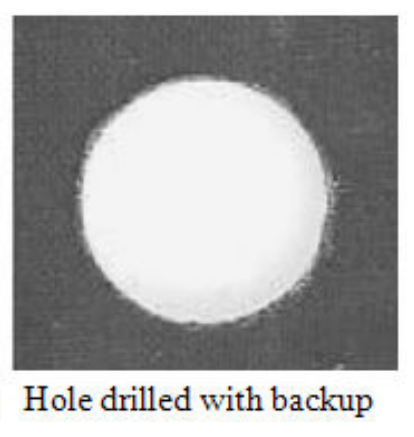

Fig. 1: (a) Chip removal problem when drilling Ti-6Al-4V [8] and (b) Effect of backup material when drilling CFRP using saw drill [9]

\section{Experimental work}

\section{Experimental design, test array and operating parameters}

The experimental work comprised a fractional factorial design using a modified L18 Taguchi orthogonal array (OA) involving variation in machining environment, drill coating, cutting speed and feed rate; see Table 1 for control variables and their associated levels together with Table 2 for the test program. Due to inherent operating parameter limitations when drilling titanium alloys in comparison to aluminium and CFRP materials, a dual level speed regime had to be specified. Here, the cutting speed when drilling through the CFRP and Al sections of the stack was twice that utilised for the Ti segment and this is denoted in Table 1 as $\mathrm{X} / \mathrm{Y}$, where $\mathrm{X}$ refers to the cutting speed used with $\mathrm{Ti}$ and $\mathrm{Y}$ indicates the value employed for CFRP and Al. In the current trials, 3 levels of cutting speed were evaluated; $20 / 40 \mathrm{~m} / \mathrm{min}, 40 / 80 \mathrm{~m} / \mathrm{min}$ and $60 / 120 \mathrm{~m} / \mathrm{min}$ respectively. Similarly, three different feed rates $(0.05,0.10$ and $0.15 \mathrm{~mm} / \mathrm{rev})$ were investigated, however unlike cutting speed this parameter was held constant when drilling through the entire stack. In addition to uncoated tungsten carbide (WC) drills, the influence of a CVD diamond coating and a hardmetal C7 layer was also assessed. The CVD diamond coating was supplied by Cemecon and had a microhardness of $10,000 \mathrm{HV}$ coupled with a maximum operating temperature of $700^{\circ} \mathrm{C}$. The nanocomposite structured $\mathrm{C} 7$ product by Unimerco consists of nano-crystalline AlTiN grains embedded in an amorphous matrix of silicon nitride $\left(\mathrm{Si}_{3} \mathrm{~N}_{4}\right)$, which provides a high oxidation limit (up to 
$\left.1100^{\circ} \mathrm{C}\right)$ together with a hardness of $45 \mathrm{GPa}(4600 \mathrm{HV})$. Trials were performed either in a spray mist environment or under flood coolant conditions (wet).

Table 1: Process control variables and their levels

\begin{tabular}{||c||c||c|c||}
\hline \hline \multicolumn{1}{|c|}{ Factor } & \multicolumn{3}{|c|}{ Levels } \\
\hline \hline Cutting environment (A) & \multicolumn{2}{|c|}{ Wet } & \multicolumn{2}{c|}{ Spray mist } \\
\hline \hline Drill coating $(\mathrm{B})$ & Uncoated WC & CVD diamond coated WC & C7 coated WC \\
\hline \hline Cutting speed $(\mathrm{C})$ & $20 / 40$ & $40 / 80$ & $60 / 120$ \\
Ti/CFRP \& Al [m/min] & $(1000 / 2000 \mathrm{rpm})$ & $(2000 / 4000 \mathrm{rpm})$ & $(3000 / 6000 \mathrm{rpm})$ \\
\hline \hline Feed rate $(\mathrm{D})[\mathrm{mm} / \mathrm{rev}]$ & 0.05 & 0.1 & 0.15 \\
\hline \hline
\end{tabular}

Table 2: Modified L18 OA for the test program.

\begin{tabular}{|c|c|c|c|c|}
\hline $\begin{array}{c}\text { Test } \\
\text { no. }\end{array}$ & $\begin{array}{c}\text { Environment } \\
\text { condition }\end{array}$ & Drill coating & $\begin{array}{c}\text { Cutting speed } \\
{[\mathrm{mm} / \mathrm{min}]}\end{array}$ & $\begin{array}{l}\text { Feed rate } \\
{[\mathrm{mm} / \mathrm{rev}]}\end{array}$ \\
\hline 1 & \multirow{9}{*}{ Wet cutting } & \multirow{3}{*}{ Uncoated } & $20 / 40$ & 0.05 \\
\hline 2 & & & $40 / 80$ & 0.10 \\
\hline 3 & & & $60 / 120$ & 0.15 \\
\hline 4 & & \multirow{3}{*}{$\begin{array}{l}\text { CVD diamond } \\
\text { coated }\end{array}$} & $20 / 40$ & 0.05 \\
\hline 5 & & & $40 / 80$ & 0.10 \\
\hline 6 & & & $60 / 120$ & 0.15 \\
\hline 7 & & \multirow{3}{*}{ C7 coated } & $20 / 40$ & 0.10 \\
\hline 8 & & & $40 / 80$ & 0.15 \\
\hline 9 & & & $60 / 120$ & 0.05 \\
\hline 10 & \multirow{9}{*}{ Spray mist } & \multirow{3}{*}{ Uncoated } & $20 / 40$ & 0.15 \\
\hline 11 & & & $40 / 80$ & 0.05 \\
\hline 12 & & & $60 / 120$ & 0.10 \\
\hline 13 & & \multirow{3}{*}{$\begin{array}{l}\text { CVD diamond } \\
\text { coated }\end{array}$} & $20 / 40$ & 0.10 \\
\hline 14 & & & $40 / 80$ & 0.15 \\
\hline 15 & & & $60 / 120$ & 0.05 \\
\hline 16 & & \multirow{3}{*}{ C7 coated } & $20 / 40$ & 0.15 \\
\hline 17 & & & $40 / 80$ & 0.05 \\
\hline 18 & & & $60 / 120$ & 0.10 \\
\hline
\end{tabular}

Workpiece materials, tooling, equipment and test procedure

Workpiece material was supplied in $30 \mathrm{~mm}$ high stacks comprising CFRP laminates sandwiched between titanium and aluminium alloy plates, each of which were approximately $\sim 10 \mathrm{~mm}$ thick. The titanium alloy was an annealed Ti-6Al-4V while the aluminium was similarly an aerospace grade with the designation Al 7050 T7451 AMS4050 having a chemical composition of 89\%Al, $6 \% \mathrm{Zn}, 2 \% \mathrm{Cu}, 2 \% \mathrm{Mg}$ and the remaining $1 \%$ consisting of minor elements. The CFRP employed unidirectional (UD), $0.125 \mathrm{~mm}$ thick carbon fibre prepregs (Cytec 977-2/HTS), which were manually laid-up with a symmetric fibre orientation of $45^{\circ} / 0^{\circ} / 135^{\circ} / 90^{\circ} / 45^{\circ} / 0^{\circ}$. A glass scrim film $(100 \mu \mathrm{m})$ was then applied to both sides of all plates prior to curing in an autoclave to prevent galvanic corrosion of the laminate surfaces. The Ti, CFRP and Al materials were bonded using a strong adhesive film (3M AF163) and cut into square specimens measuring $120 \times 120 \mathrm{~mm}$ (see Fig. 2) to fit a rigid, bespoke fixturing plate with pre-drilled clearance holes. Additional samples $(17 \mathrm{~mm}$ $\mathrm{x} 120 \mathrm{~mm}$ ) were also produced to accommodate cutting force measurement and for subsequent hole quality/integrity analysis (entry/exit delamination, hole size, out of roundness etc.). Here, the stacks 
were bolted using M6 screws to provide additional security in order to prevent material separation during drilling.

All drills were $6.35 \mathrm{~mm}$ in diameter with a maximum cutting length of $40 \mathrm{~mm}$ and corresponding shank size of $8 \mathrm{~mm}$. Tool geometry was kept constant with helix and point angles of $30^{\circ}$ and $130^{\circ}$ respectively. The machining tests were carried out on a Matsuura FX-5 CNC high speed machining centre equipped with a spindle capable of $20,000 \mathrm{rpm}$ and maximum power rating of $15 \mathrm{~kW}$. A Renishaw touch trigger probe was utilised for tool length setting. The cutting fluid was a water/oil emulsion containing 7-8\% volume solution of soluble oil (Hocut 3380), which was delivered to the cutting zone (pump pressure of 70 bar and flow rate of $\sim 151 / \mathrm{min}$ ) via a retrofit through coolant spindle adaptor incorporating a BT40 tool holder. Spray mist environment (external supply as opposed to through spindle) was generated using a 'Jet Thrust' particle coolant unit (two fluid device; coolant and lubricant) which involved a mixture of soluble oil coolant and mineral oil lubricant. The system combined the soluble oil cutting fluid (at a flow rate of $\sim 50 \mathrm{ml} / \mathrm{min}$ ) with the mineral oil lubricant (at a flow rate of $\sim 10 \mathrm{ml} / \mathrm{min})$ following which compressed air $(\sim 3$ bar) was used to discharge the mist at a velocity of $\sim 20 \mathrm{~m} / \mathrm{s}$. Tool flank wear was measured using a WILD M3Z toolmaker's microscope having a XY digital micrometer platform while micrographs of the drills both in the new and worn condition were captured with a digital camera. Thrust force and torque signals were recorded using a Kistler 9273 four-component piezoelectric drilling dynamometer connected to charge amplifiers and later analysed with a PC using Dynoware software. Measurements were obtained during the first hole and subsequently at intervals of between 10-30 holes, depending on the rate of tool wear.

In the current work, drilling trials was initiated at the titanium section and moved through the CFRP to the aluminium at the bottom of the stack. This was contrary to conventional practice where cutting typically commences at the aluminium surface. Unfortunately, the latter sequence (Al/CFRP/Ti) generally results in severe damage to surfaces on the Al and CFRP portions of the stack due to sharp Ti swarf moving up the hole during chip evacuation [8], which was observed in preliminary testing under equivalent conditions carried out by the present authors. It was anticipated that operating with the current stack orientation (Ti/CFRP/Al) would improve hole surface quality. The tool life criterion was average flank wear $\left(V B_{\mathrm{B}}\right)$ of $0.3 \mathrm{~mm}$ (between the 2 main cutting lips) or tool fracture. Analysis of variance (ANOVA) and main effects plots were produced to determine the statistical significance/percentage contribution of test factors on the primary response measures which include tool life, thrust force and torque. No analysis of interactions between the factors was performed.
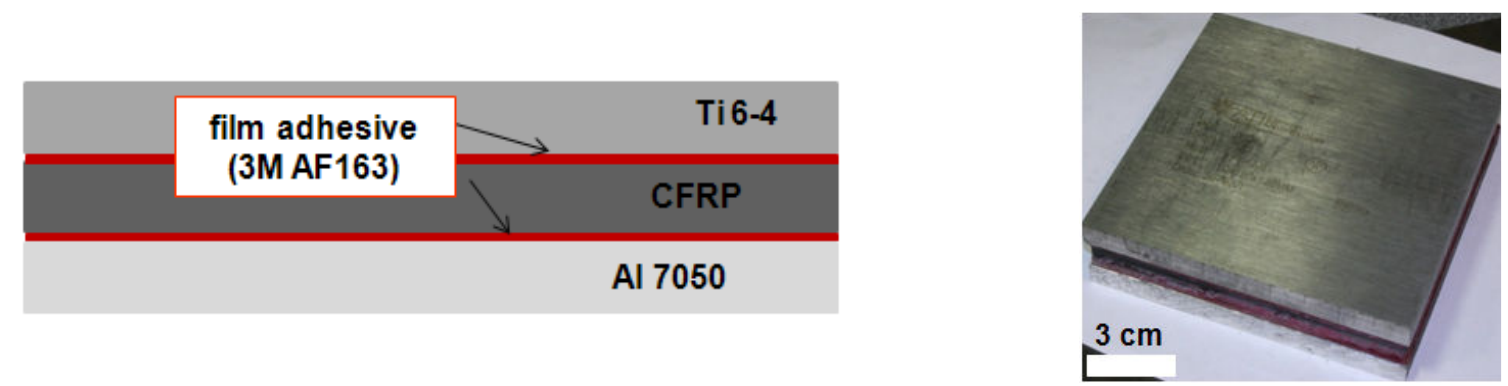

Fig. 2: (a) Schematic of stack cross section and (b) $30 \mathrm{~mm}$ thick stack of Ti/CFRP/Al stacks cut into $120 \times 120 \mathrm{~mm}$ workpiece samples

\section{Results and discussion}

Fig. 3 shows tool flank wear progression versus number of drilled holes under (a) wet/flood coolant and (b) spray mist conditions. Best performance (310 holes) was obtained when cutting wet using an uncoated drill at $20 / 40 \mathrm{~m} / \mathrm{min}$ with a corresponding feed rate of $0.05 \mathrm{~mm} / \mathrm{rev}$. All trials performed at the lowest cutting speed under spray mist application experienced elevated noise levels due to rubbing between the tool and titanium layer, regardless of drill coating. Tool life was poor in comparison and the number of drilled holes did not exceed 100, with test cessation brought 
about by catastrophic tool failure (discussed later in the paper). Further tests at intermediate and high cutting speed using the uncoated drill exacerbated the squealing resulting in even shorter tool lives with sparking also observed. Based on this, trials involving CVD diamond and C7 coated drills at intermediate and high speeds were also expected to give a similarly undesirable performance and were therefore excluded from the current experimental plan.
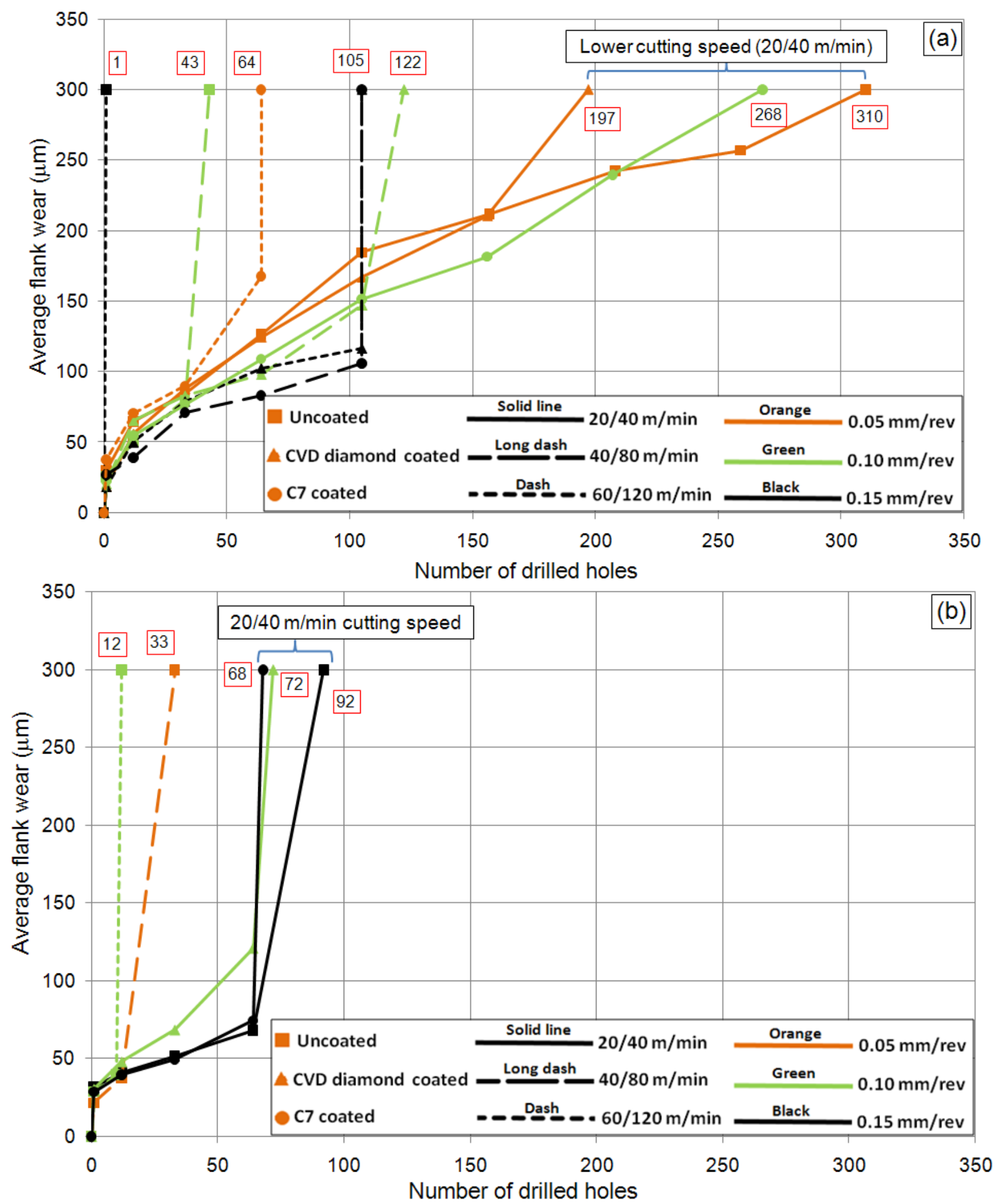

Fig. 3: Tool wear curves for tests performed using (a) flood coolant and (b) spray mist. 
Fig. 4(a) details tool life results as a function of operating parameters and drill coating for experiments carried out with flood coolant application. Cutting speed had an overriding influence on tool life with a steep decline in the number of drilled holes as the parameter was trebled from $20 / 40 \mathrm{~m} / \mathrm{min}$ to $60 / 120 \mathrm{~m} / \mathrm{min}$, irrespective of the magnitude of feed rate or tool coating. This trend was particularly evident when uncoated drills were used where the tool failed after only one hole when machining at the highest speed level. Fig. 4(b) shows sample micrographs of worn drills for the different coating types at varying test parameters. Peeling of the CVD diamond coating was apparent in all tests involving the tool and typically occurred within the first several holes drilled, however this did not appear to be a limiting factor in terms of tool life, especially at the lowest cutting speed.
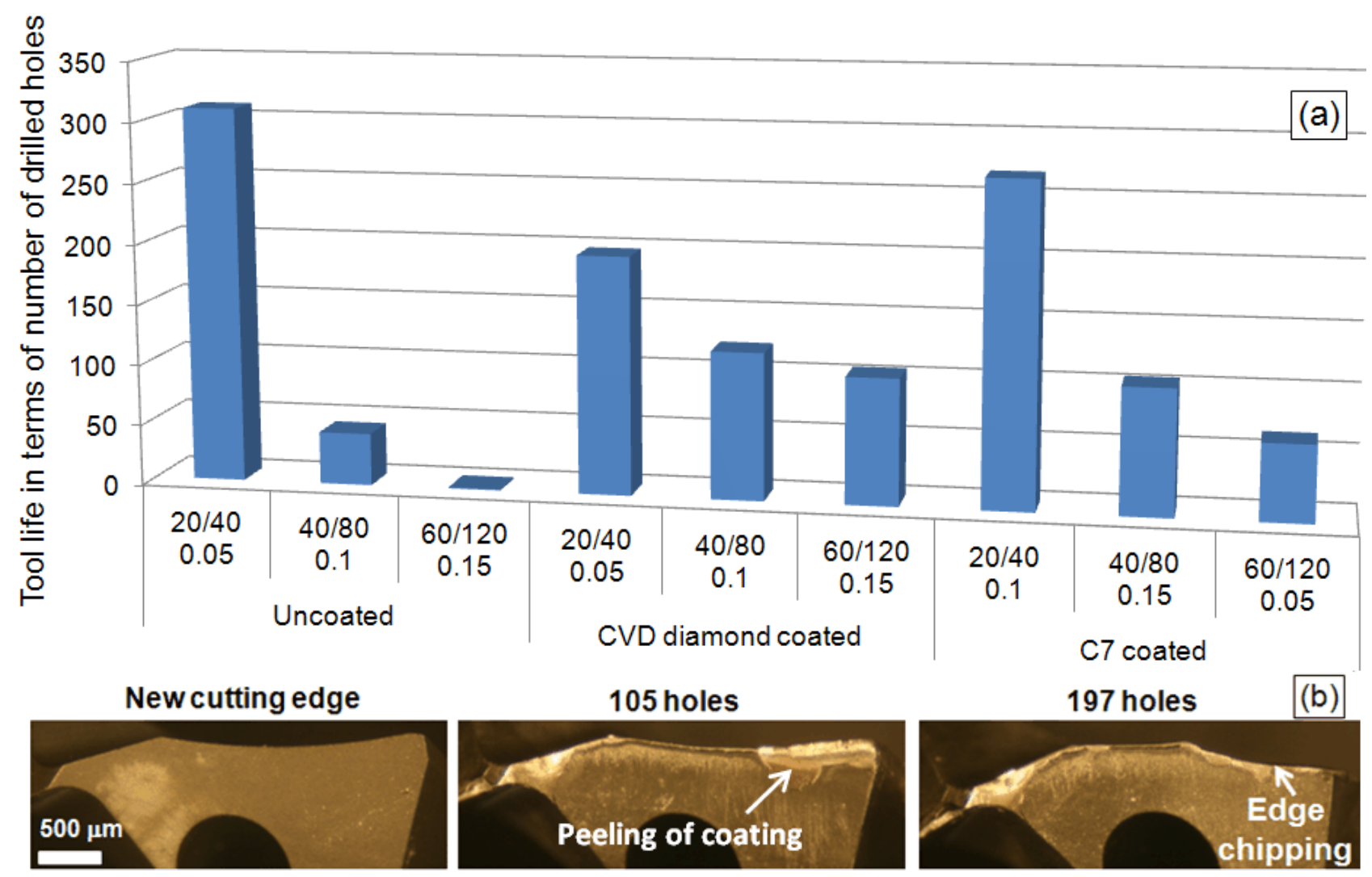

CVD diamond coated drill $-20 / 40 \mathrm{~m} / \mathrm{min}-0.05 \mathrm{~mm} / \mathrm{rev}$ - wet cutting

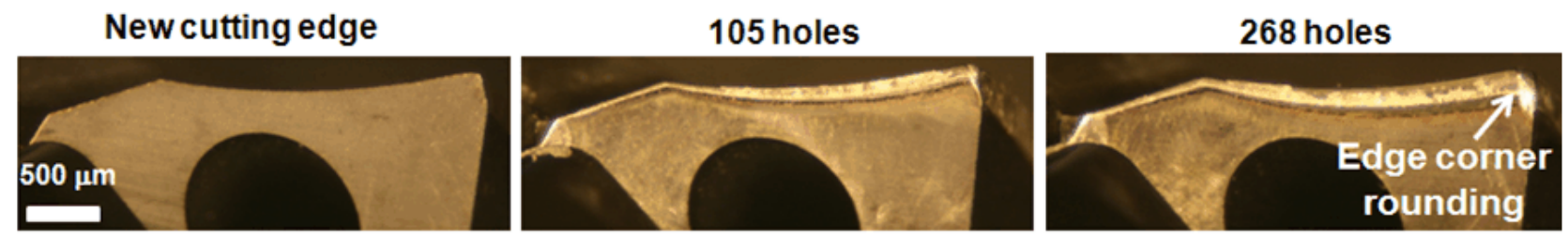

C7 coated drill $-20 / 40 \mathrm{~m} / \mathrm{min}-0.1 \mathrm{~mm} / \mathrm{rev}$ - wet cutting

New cutting edge

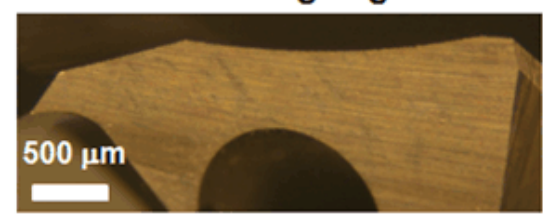

Uncoated drill $-20 / 40 \mathrm{~m} / \mathrm{min}-0.15 \mathrm{~mm} / \mathrm{rev}$ - spray mist cutting
64 holes

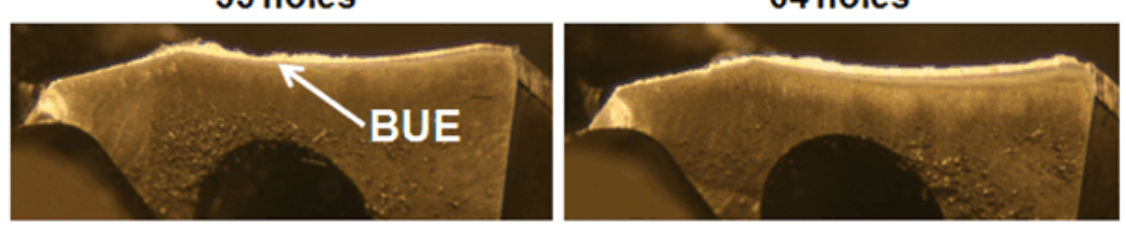

(b) sample flank wear micrographs. 
The 3 drills employed at 20/40 $\mathrm{m} / \mathrm{min}$ under wet conditions generally exhibited steady flank wear evolution up to the end of life criterion, although edge chipping was seen with the CVD diamond coated tool after 197 holes. All other drills however experienced sudden tool failure through various mechanisms. These included tool breakage at the cutting portion which was thought to be associated with high torque values caused by adhesion of titanium to the tool in addition to clogging of drill flutes by chips (Tests 2, 3, 10, 13 and 16), fracture of cutting lips as a result of built up edge (BUE) formation/smearing (Tests 4, 5, 6 and 9) and severe cutting edge corner rounding due to the abrasion by CFRP (Test 8 ). BUE was predominantly present in trials involving spray mist application and was found to form mainly on the primary cutting lips as well as drill margins. A likely reason for this was the poor access/transport of the spray mist lubricant to the cutting zone, especially as the drill moved deeper towards the aluminium layer of the stack.

The main effects plot and corresponding ANOVA table for tool life is shown in Fig. 5. The former suggests that maximum number of holes would be obtained by operating at the lowest cutting speed and feed rate under wet conditions, independent of drill coating. However, the ANOVA highlighted that cutting speed and environment were the only statistically significant factors at the 5\% level with percentage contribution ratios (PCR's) of $41.9 \%$ and $31.6 \%$ respectively. A relatively high residual error value (26.3\%) was also observed, most probably due to the premature failure of drills encountered in several of the tests together with possible interaction between factors. The considerable influence of cutting speed on tool life can be attributed to the probable increase in temperature at higher drilling speeds coupled with the poor thermal conductivity of both titanium $(6.7 \mathrm{~W} / \mathrm{mK})$ and CFRP $(\sim 1 \mathrm{~W} / \mathrm{mK}$ perpendicular to the fibre direction), which restricted the dissipation of heat from the cutting zone. Similarly, the greater cooling capacity of the high pressure (70 bar) through coolant spindle system was thought to partially account for the higher average tool life achieved, despite the superior lubricity of the spray mist configuration.

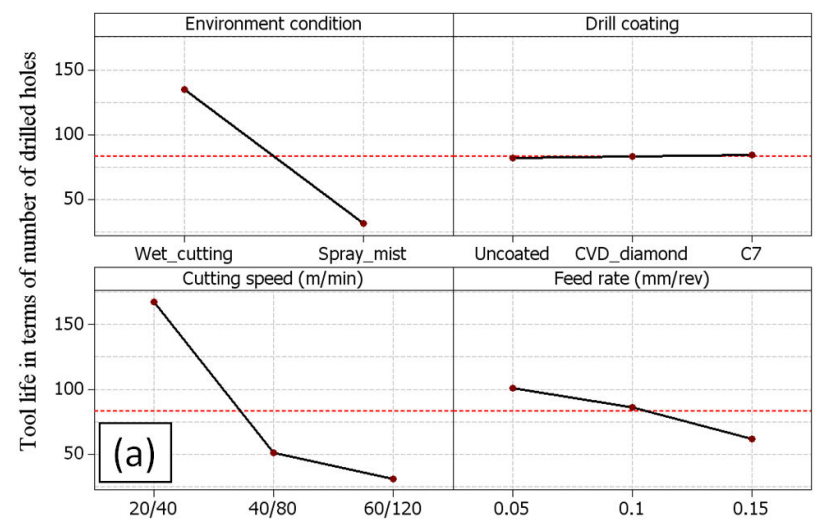

\begin{tabular}{|c|c|c|c|c|c|c|}
\hline Factor & DF & SS & Exp SS & F & P & PCR \\
\hline A & 1 & 48568 & 45986 & 18.81 & $0.001 *$ & 31.6 \\
\hline B & 2 & 30 & -5134 & 0.01 & 0.994 & 0.0 \\
\hline C & 2 & 66136 & 60972 & 12.81 & $0.002 *$ & 41.9 \\
\hline D & 2 & 4686 & -478 & 0.91 & 0.434 & 0.0 \\
\hline Error & 10 & 25820 & & & & 26.3 \\
\hline Total & 17 & 145241 & & & & \\
\hline $\begin{array}{l}\text { DF=Degrees of freedom } \\
\text { SS=Sum of squares } \\
\text { Exp SS=Expected sun of squares }\end{array}$ & $\begin{array}{l}\text { F=F-test value } \\
\text { P=Probability }\end{array}$ \\
* SCR=Percentage \\
contribution ratio (b) at the 5\% level
\end{tabular}

Fig. 5: (a) Main effects plot and (b) ANOVA results for tool life in terms number of drilled holes.

Fig. 6(a) displays the typical thrust force and torque signals obtained when drilling a single hole through the Ti/CFRP/Al stack using flood coolant. The momentary drop in thrust force relates to a programmed retraction $(1 \mathrm{~mm})$ of the drill as it initially penetrates the CFRP layer in order to accommodate the transition of tool rotational speed. The progression of average thrust forces and torque with respect to number of drilled holes for the individual material layers (Ti, CFRP \& Al) in Test 1 are detailed in Fig. 6(b). In general, the force levels recorded when drilling Ti were $\sim 3$ times greater compared to those when cutting CFRP and Al, which were approximately equal over the duration of the test, except when tools were in the new condition. This response was representative in the majority of trials which were either not subject to or prior to the onset of catastrophic tool failure. In contrast, torque was found to be lowest in the CFRP followed by $\mathrm{Al}$ and $\mathrm{Ti}$, which can be explained by the tendency for both titanium and aluminium swarf to adhere onto drill edges and lips. While there were notable rises in thrust forces with worn tools (at the point of test cessation) over new drills of the order of 5, 7 and 16 times in Al, Ti and CFRP respectively, corresponding 
torque levels only increased by a factor of 3,4 and 5. The greater sensitivity of thrust force to changes in tool wear compared to torque was in accordance with results from previous work by Lin and Ting [11]. In any event, the maximum thrust force attained with worn tools was approximately $2200 \mathrm{~N}$ while torque did not exceed $600 \mathrm{~N} . \mathrm{cm}$ over the test conditions employed.

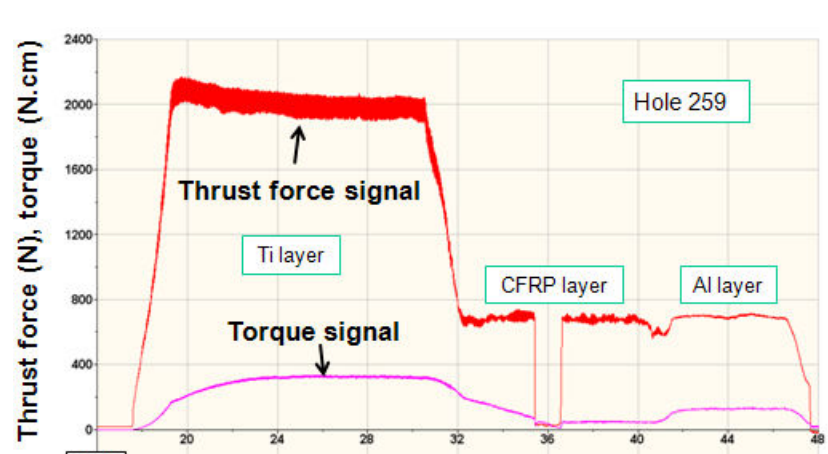

(a)

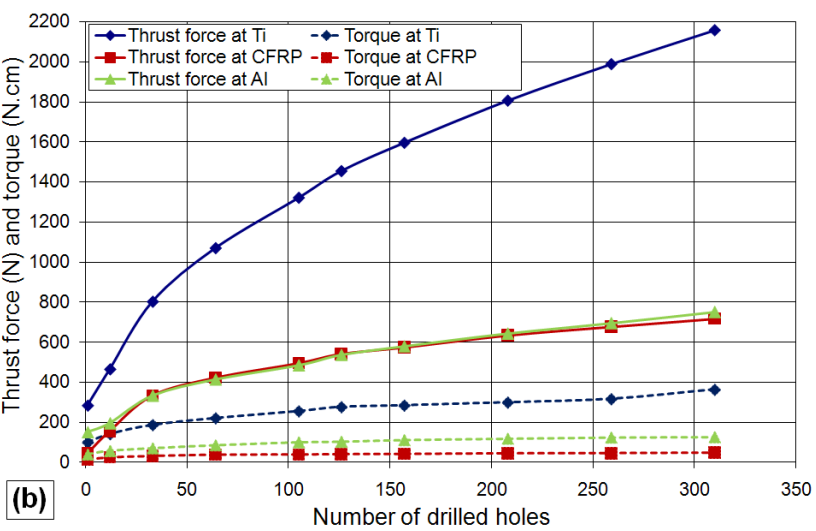

Fig. 6: (a) Typical thrust force / torque signature and (b) evolution of thrust force / torque versus number of drilled holes in Test 1.

Fig. 7 details the thrust forces recorded in the 3 different material layers following the first hole drilled (new tool) for each test. As outlined previously, the forces associated with Ti (ranging from $285-600 \mathrm{~N}$ depending on operating parameters) were considerably higher compared to both Al $(135-342 \mathrm{~N})$ and CFRP $(44-190 \mathrm{~N})$ when cutting with flood coolant. This however was not the case with the spray mist environment, where thrust forces in the Al layer $(234-540 \mathrm{~N})$ were comparable, and in some cases exceeded the values produced in the Ti alloy $(239-426 \mathrm{~N})$. The results would appear to support the earlier assertion that reduced levels of spray mist lubricant penetrated to the Al layer.

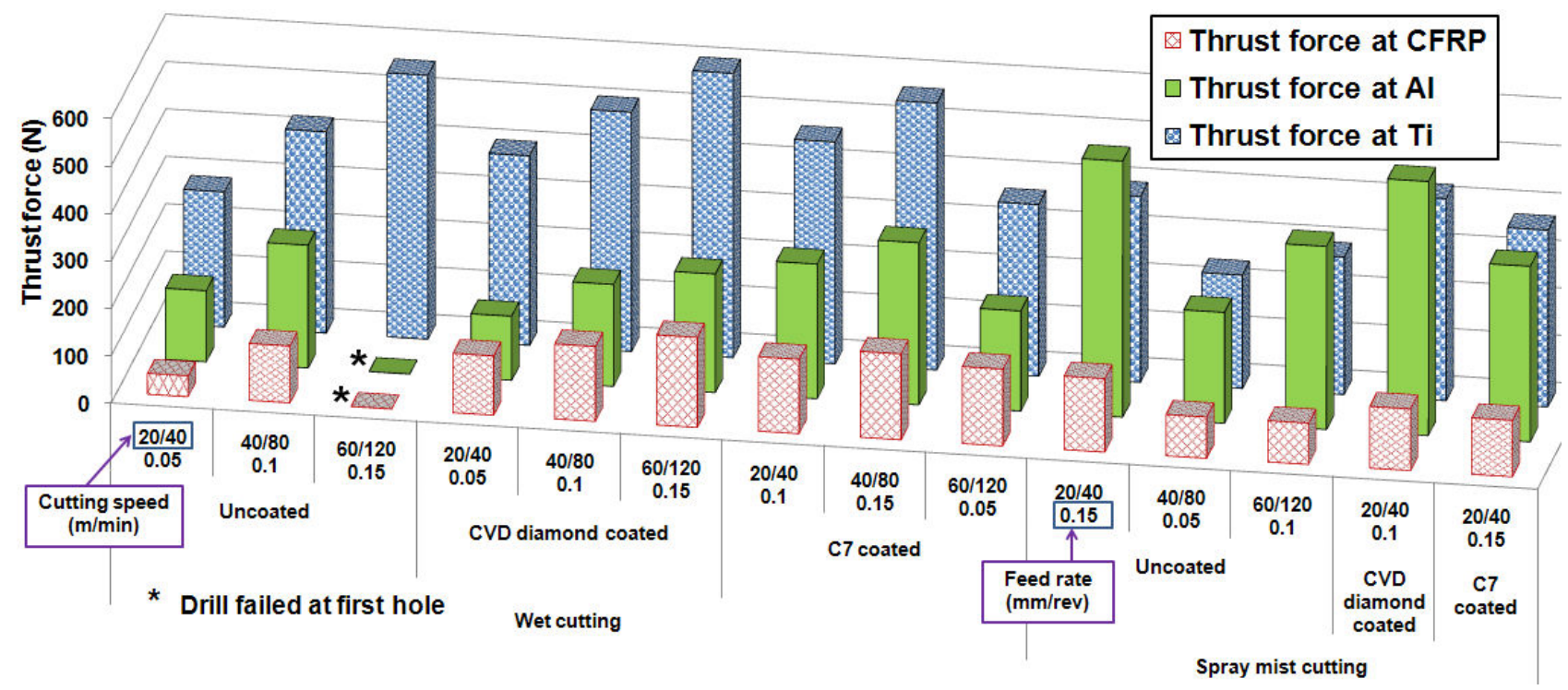

Fig. 7: Thrust force results for new tool (first hole).

The main effects plot for thrust force and torque when cutting through Ti/CFRP/Al stacks during the first hole is shown in Fig. 8. In terms of thrust force, all three materials exhibited near identical trends with respect to changes in control variable levels. The sole exception was the response of aluminium where thrust force was higher with spray mist as opposed to wet conditions, in contradiction to results seen for titanium and carbon fibre composite. Related ANOVA data highlighted the fact that feed rate had a significant impact on thrust force generation in all 3 layers with PCR's of $40 \%, 31 \%$ and $20 \%$ for Ti, CFRP and $\mathrm{Al}$ respectively. The cutting environment was 
also a major contributing factor when drilling the Ti and Al with PCR's of $22 \%$ and $32 \%$, while drill coating was only prominent in respect of the Ti layer (PCR of 23\%). Investigation of torque measurements revealed no discernable pattern between the three elements of the stack in relation to the environmental condition, drill coating or cutting speed. As expected, torque values for each material increased with increasing feed rate although this parameter was only significant for Ti and Al, albeit with a dominant PCR of $72 \%$ for Ti and a considerably lower effect of $24 \%$ for the Al. Conversely, cutting environment had the greatest influence in the Al (41\%) section followed by CFRP (24\%) and Ti. As anticipated, cutting speed showed a significant effect on torque with the CFRP, which agrees with recently published work on small hole drilling of carbon fibre composites [12].
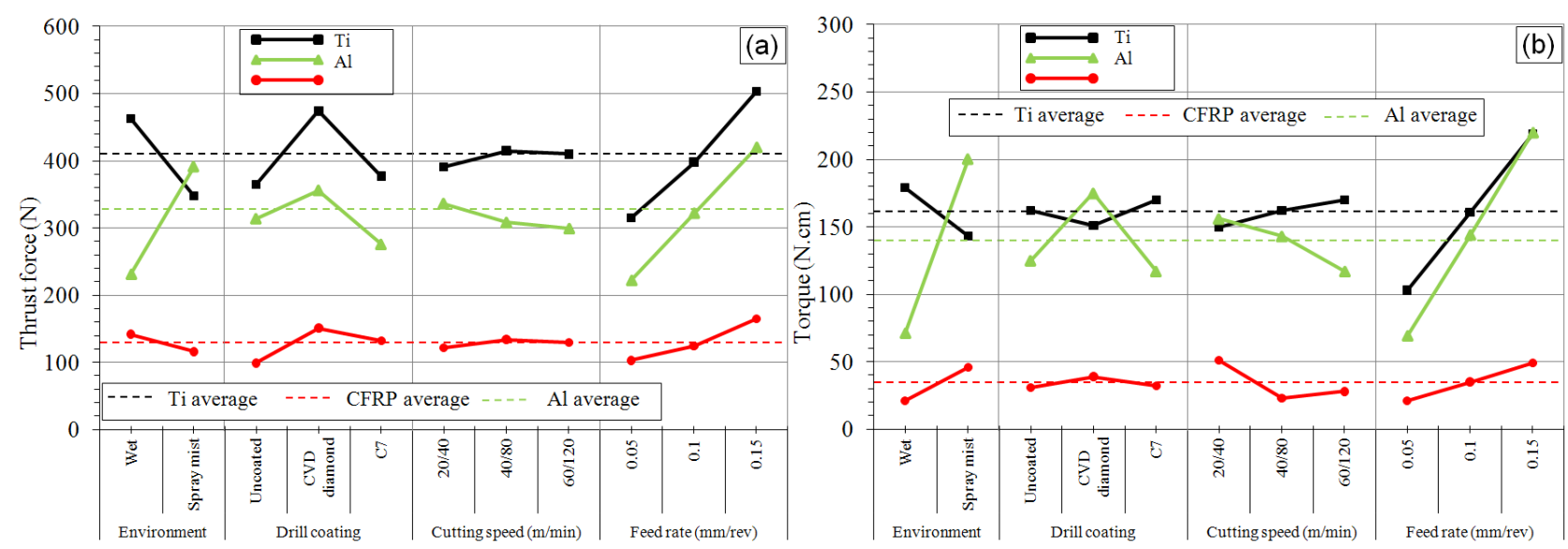

Fig. 8: Main effects plot for (a) means of thrust force and (b) means of torque after first hole.

\section{Conclusions}

- Tool life in terms of number of drilled holes was primarily dependent on cutting speed and cutting environment. In the current work, up to 310 holes in Ti/CFRP/Al stack was achieved when employing an uncoated drill at low cutting speed $(20 / 40 \mathrm{~m} / \mathrm{min})$ and feed rate $(0.05$ $\mathrm{mm} / \mathrm{rev}$ ) under wet cutting conditions.

- When wet cutting with new drills, thrust force was highest in the titanium layer (up to 600 $\mathrm{N})$ while lowest levels were recorded with the CFRP material $(190 \mathrm{~N})$. Tests involving spray mist application however generally highlighted greater thrust forces in the aluminium alloy. The corresponding ANOVA showed that feed rate and environment condition were statistically significant at the 5\% level in relation to thrust force for both $\mathrm{Ti}$ and $\mathrm{Al}$.

- Feed rate and environment condition was also found to be prevalent factors in torque generation for the Ti and Al layers of the stack. While feed rate had an overwhelming $72 \%$ influence in the former material, environment condition was the principal variable affecting torque with the latter.

- The CFRP did not appear to have an overriding effect on tool life when drilling multi-layer composite/metallic stacks based on the majority of tool failure mechanisms observed.

- No benefits in terms of tool life, thrust force or torque was realised when using the CVD diamond or C7 hardmetal coating over uncoated WC drills.

- In general, the use of high pressure through spindle coolant ( 70 bar $)$ is recommended over external spray mist application due to the superior cooling properties and improved access to the cutting zone with the former. 


\section{Acknowledgements}

The authors would like to thank the School of Mechanical Engineering, University of Birmingham and Universities UK for the provision of funding through the ORSAS scheme. We are further indebted to GKN Aerospace (Isle of Wight), Unimerco Ltd. and Element Six for additional financial and technical support.

\section{References}

[1] H. Zhang, W. Chen, D. Chen and L. Zhang: Key Eng. Mater. Vol. 196 (2001), p. 43.

[2] J.P. Davim and P. Reis: Compos. Struct. Vol. 59(4) (2003), p. 481.

[3] C.C. Tsao and H. Hocheng: Int. J. Mach. Tools Manuf. Vol. 44(10) (2004), p. 1085.

[4] C. Murphy, G. Byrne and M.D. Gilchrist: Proc. Inst. Mech. Eng. Part B J. Eng. Manuf. Vol. 216(2) (2002), p. 143.

[5] W. Konig, Ch. Wulf, P. Graß and H. Willerscheid: Ann. of the CIRP Vol. 34/2 (1985), p. 537.

[6] L.B. Zhang, L.J. Wang and X.Y. Liu: Proc. Inst. Mech. Eng. Part B J. Eng. Manuf. Vol. 215(2) (2001), p. 135.

[7] K.Y. Park, J.H. Choi and D.G. Lee: J. Compos. Mater. Vol. 29(15) (1995), p. 1988.

[8] E. Brinksmeier and R. Janssen: CIRP Ann., Manuf. Technol. Vol. 51/1 (2002), p. 87.

[9] C.C. Tsao and H. Hocheng: Int. J. Mach. Tools Manuf. Vol. 45(11) (2005), p. 1261.

[10]I.W. Park and D.A. Dornfeld: J. Eng. Mater. Technol. Vol. 122(2) (2000), p. 229.

[11] S.C. Lin and C.J. Ting: Wear Vol. 180(1-2) (1995), p. 53.

[12]I.S. Shyha, D.K. Aspinwall, S.L. Soo and S. Bradley: Int. J. Mach. Tools Manuf. Vol. 49(1213) (2009), p. 1008. 